\title{
ELEVEN \\ Provider plurality and supply-side reform
}

Rod Sheaff and Pauline Allen

\section{Polymorphous plural providers}

$\begin{array}{ll}\text { Not only healthcare financing but also its provision was nationalised } & 14\end{array}$ when the NHS was founded. Besides guaranteeing access to healthcare, 15 Bevan and the other founders also intended to - and eventually 16 largely did - ' level up' a supply side comprised of diversely-owned 17 providers which provided correspondingly diverse levels of service 18 access, quality and responsiveness to healthcare needs. Since 1979 neo- 19 liberal 'reforms' of the NHS have had a supply side component, that 20 of introducing 'provider plurality' under which a range of differently- 21 owned organisations provide NHS-funded services: 22

1. public firms, that is, state-owned providers (for example, NHS 24 trusts) with a degree of financial autonomy and discretion in their 25 use of resources.

2. professional partnerships (for example, most general practices), 27 which a group of professionals jointly own and manage, and which 28 employ other staff. $\quad 29$

3. Shareholder-owned, dividend-maximising firms including: $\quad 30$ a) private equity firms, whose shares are not publicly traded. $\quad 31$

b) Corporations, whose shares are publicly traded. 32

4. proprietary (that is, owner-managed firms), whose shares are not 33 usually publicly traded. 34

5. social enterprises, an ill-defined category ranging from not-for- 35 profit providers which differ from corporations mainly in not 36 distributing profits to shareholders to organisations whose workforce $\quad 37$ and/or consumers have a voice in controlling the organisation 38 (Allen et al, 2011). 39

6. charitable, voluntary and self-help organisations which depend 40 heavily on volunteer labour. $\quad 41$ 
7. co-operatives and mutuals, democratically controlled by their workforce, consumers or subscribers.

In the circumstances that most NHS services have hitherto been provided by public organisations and professional partnerships, proposals for greater provider diversity mean shifting the proportion towards types (3) to (7) above. Whatever the effect on healthcare supply, such a contentious policy has already greatly increased the supply of euphemism, confusion and obfuscation in health policy debates. This chapter attempts to give an overview of the empirical patterns of development, and unpick some of the conceptual confusions.

\section{Provider plurality and supply side reform before 2010}

Until the late 1970s, the most salient English health policy debates were electoral bidding competitions about spending on the NHS and about the effect of private medical practice on NHS waiting lists. Parliament occasionally heard proposals to retract public funding and provider ownership at the margins of the NHS, raise prescription and other NHS charges, retain 'amenity' beds in NHS hospitals (for a fee patients could obtain better 'hotel' services), and allow consultants greater private practice. Mostly these policies had little practical impact but served, rather, a symbolic function of preserving the idea of the normality and legitimacy of plural provision and private payment for healthcare, not least for parts of the Conservative Party and likeminded pressure groups who were still sceptical about an NHS whose efficiency, popularity and indeed existence were living disproof of some of their policy, economic and moral principles.

\section{Version 1: Provider plurality}

With the Thatcher government (1979) their moment came, but also a dilemma. Financially and ideologically (Bacon and Eltis, 1976; Letwin, 1988), such governments disliked living with the welfare state, but electorally they could not live without it (Offe, 1982); Its 'flagship', the NHS, was too popular for direct attack. As their main intellectual foundation, NHS 'reform' policies since 1979, including provider plurality, have what some orthodox economists call the 'doctrine of the second best': if one cannot establish a conventional market, the next best thing is to establish institutions whose market 'distortions', taken together, minimise the overall deviation from perfect competition (Lipsey and Lancaster, 1956). This doctrine suggests the construction 
of quasi-markets (Enthoven, 1985; Bartlett and Le Grand, 1993) in which the state, social insurer or similar body purchases services on behalf of the consumer (Allen 2013) and in which plural providers of healthcare compete by stimulating innovation, improving healthcare quality and/or reducing of healthcare costs. For the NHS, the UK government envisaged District Health Authorities (DHAs) and GP fundholders purchasing healthcare on behalf of patients, with providers competing for contracts and thus for income (Department of Health, 1989).

From 1991 both these purchasers were allowed to commission nonNHS providers. Using Waiting List Initiative funds, DHAs could purchase private hospital treatment for patients who had been more than a year on NHS waiting lists, although these purchases remained only a small proportion of NHS in-patient work (see Chapter 12). Few GP fundholders commissioned private care for their patients. Economists often assume that in order to compete successfully in a quasi-market, providers need to take on certain more corporate characteristics: greater managerial discretion, provider retention of profits and losses, and governance through a Board of Directors (Harding and Preker 2000). Except for general practices, NHS providers were therefore reconstituted as NHS trusts partly on these lines but, importantly, not (yet) in respect of profit retention. From 1993 the Department of Health also encouraged private-public joint ventures, removing the requirement to assess them against a fully NHS-funded alternative (NHS internal Executive Letter EL(93)37, issued by the Department of Health in London in 1993). Soon after, the Private Finance Initiative (PFI) followed. NHS trusts made turnkey contracts with consortia of corporations and private equity firms to plan, finance, build and hospitals, and to provide the ancillary services, on-site shops and car parking. The trust paid the consortia for these but retained clinical budgets, income and management. To financially justify PFI hospital schemes sometimes required trusts to under-estimate future caseload and over-estimate clinicians' future productivity, so as to under-estimate the required beds (Pollock et al, 1999). The 1996 NHS (Residual Liabilities) Act made the Secretary of State for Health guarantor of PFI schemes in the NHS (Hellowell, 2014).

When the GPs' contract with the NHS was revised in 1990, general practices were no longer obliged to do their own out-of-hours $(\mathrm{OOH})$ work: they could arrange, or pay, for another doctor to do so. Corporate deputising services developed as a result, but still more did GP cooperatives, some of which later diversified into providing medical call-centres and walk-in treatment centres (Sheaff et al, 
2012). The 1997 Personal Medical Services (PMS) scheme opened up primary medical care to nurse-led providers, corporate and proprietary provision. Initially there were few such providers (for instance, there were probably fewer than 50 nurse-led general practices) but provider plurality had been extended into primary medical care.

\section{Version 2: the Third Way}

By 1997 the Labour Party had essentially accepted provider plurality, indeed the whole principle of an NHS quasi-market. Labour presented its 'Third Way' health policies as departing both from some aspects of Conservative 'reforms' (especially GP fundholding) but also and more significantly for provider plurality - from Bevan's reliance upon nationalised healthcare providers. Nevertheless the Third Way was a mixed blessing for provider plurality. PFI 'Unitary charges' (management fees which an NHS trust paid the PFI consortium) were set at $2.5 \%$ pa of the project's capital cost or the rate of inflation if higher. From 2004, one change to the NHS contract with GPs (the General Medical Services (GMS) contract) was to make general practices, not named GPs, the contract signatories so that practices could change ownership without jeopardising their NHS contract. General practices were also permitted to opt out of $\mathrm{OOH}$ work: a death-sentence for many cooperatives. Some closed, others converted to proprietary or social enterprise status.

\section{Version 3: or rather, version 1 recycled}

By 2001 English health 'reforms' had become more overtly similar to pre-1997 policies, but New Labour took provider plurality further. New Labour's post-2001 reforms were their response to what they perceived as the failure of hierarchically-structured NHS providers during 1997-2001; and to what they perceived as the specific deficiencies of the Conservatives' internal market of the 1990s, particularly regarding motivation and incentives on the supply side. Indeed New Labour re-articulated the Conservatives' objectives for the first NHS quasi-market of the 1990s, and the principle of an NHS quasi-market itself, as 'four inter-related pillars of reform ... designed to embed incentives for continuous and self sustaining improvement' and produce 'better quality, better patient experience, better value for money and reduced inequality' (Department of Health, 2007b). These pillars were: demand side reform; transactional reform; system management and regulation; and supply side reform, including 'more 
diverse providers with more freedom to innovate and improve services' 1

(Department of Health, 2007b). 2

Since the coalition and Conservative governments have continued 3 most of them, it is worth describing these policies more fully.

1. Demand side reform: Under the 'Patient Choice' policy NHS 6 patients could select from a range of hospitals, one of which had to 7 be independent (Department of Health, 2007a). Under the 'Any 8 Willing Provider' principle, patients could choose any hospital 9 provider accredited by the NHS. Patients were thought likely 10 to avoid under-performing hospitals, for whom the prospect of 11 losing funding under the cost-per-case Payment by Results pricing 12 system (see below) would create incentives to improve quality and 13 access times. Real choice, New Labour assumed, would require an 14 expansion of provider types and capacity. A similar 'Any Qualified 15 Provider' policy for community health services (CHS) followed, 16 with the aim of improving access to CHS and to allow the entry of 17 new providers. Again, patients could choose from a national list of 18 approved providers (Jones and Mays, 2013). 19

2. Transactional reform: a DRG-based system (the 'health resource 21 groups' (HRG) or 'tariff') of fixed prices for procedures, for paying 22 both public and independent hospitals was introduced (Department 23 of Health, 2007b). Although this cost-per-case system is called 24 'payment-by-results' (PbR) it is actually payment by activity. The 25 idea was to sharpen incentives and competition, with each episode 26 of care being reimbursed - if it was not lost to another provider - 27 at the national tariff rate, based on average costs. PbR was initially 28 designed to cover acute hospitals' work and has not been expanded $\quad 29$ to community or mental health services, which are still paid for on $\quad 30$ block contracts, in effect fixed budgets (Allen et al, 2014). 31

3. System management and regulation: Alongside continuing 33 hierarchical control by the Department of Health (and since 2013, 34 NHS England), the NHS quasi-market was regulated at arm's length 35 by the Cooperation and Competition Panel (CCP) which advised 36 the Department of Health in accordance with the Principles and rules 37 for cooperation and competition (Department of Health, 2010b). These 38 principles required 'providers and commissioners to cooperate to 39 deliver seamless and sustainable care to patients' and not to make 40 'agreements which restrict commissioner or patient choice against 41 patients' or taxpayers' interests'. The Care Quality Commission 42 
(CQC: formerly the Commission for Health Improvement and then the Healthcare Commission) was responsible for inspecting both public and independent providers; registering independent providers and publishing annual performance ratings for all NHS organisations. The other important regulator was (and remains) Monitor, the independent regulator of Foundation Trusts. It authorised Foundation Trusts and specified borrowing limits, ceilings on income from private treatments, the range of goods and services that could be supplied, and required financial and statistical information (Allen, 2006).

4. Supply side reform: New Labour's version of the 'public firm' idea was NHS Foundation Trusts (FTs). Being still state-owned, FTs are not independent providers, but are designed to mimic aspects of third sector providers by involving local people in their governance, and have a degree of managerial autonomy. From 2004 they were allowed to carry any operating surplus forward to the next financial year.

Commissioners were also encouraged to engage with new providers from the 'third sector' (social economy) including local voluntary groups, registered charities, foundations, trusts, non-profit social enterprises, and cooperatives (Department of Health, 2006). Finally, for profit providers were also encouraged to enter the NHS quasimarket on a larger scale. A 'Concordat' with the private hospital sector signalled that the NHS would continue purchasing private hospital treatments. Independent sector treatment centres (ISTCs), one per PCT, were set up specifically to carry out elective outpatient, daypatient and low-complexity in-patient surgery on NHS patients (House of Commons Health Select Committee, 2006). Initially the main providers were corporations: Capio (at least eight contracts), Carillon (trading as Clinicenta), Interhealth Canada, Mercury, Nations Healthcare, Netcare Healthcare, Partnership Health Group, Ramsay, Spire and Health Care UK. Some (but not all) ISTCs were subcontracted to their local NHS trust, thereby removing competition between those two providers. ISTCs were initially contracted nationally but the amount of patients treated has declined in recent years (Allen and Jones, 2011). The government also invited United Health, a major US health insurer, to pilot nurse-led case management of frail older people with frequent unplanned hospital admissions. This resulted in the 'Community Matron' system, but without further corporate involvement. 


\section{Liberating the supply side}

The current NHS reforms, designed yet again to increase the market-like behaviour of providers of care (Department of Health, 2010a), span the Coalition and current Conservative government. The coalition's Health and Social Care Act (HSCA, 2012) took effect in April 2013. It applied competition law explicitly to the NHS quasi-market (den Exter and Guy, 2014). As the new economic regulator for the whole of the NHS (not only FTs) Monitor acquired some functions of the former CCP and, along with the national competition authorities (since April 2014, the Competition and Markets Authority, or CMA), powers to enforce competition law to prevent anti-competitive behaviour and to produce a level playing field which places neither public nor private providers at any substantial advantage in competing for NHS-funded contracts. The NHS Procurement, Choice and Competition Regulations No. 2 2013 made elements of existing guidance matters for statutory regulation, including the PRCC and NHS procurement guidelines, and indicated that competitive procurement was to be preferred.

NHS Foundation Trusts were now permitted to obtain up to $49 \%$ of their income from non-NHS sources (this does not mean to have $49 \%$ private patients). They could reinvest profits from non-NHS income generation to benefit NHS patients (Monitor, n.d.). Each PCT was required to make at least three AQP contracts in 2012 (Allen and Jones, 2011), and more subsequently. Many of the PFI schemes were becoming ruinous for the NHS trusts involved, leading to attempts to buy some of the PFI schemes out. The courts ruled, however, that the government was exceeding its powers under the 2012 HSCA when it tried to spread the costs of the South London Healthcare Trust's PFI schemes (16\% of its budget; Hodge, 2013) over nearby NHS trusts who had not been party to the schemes.

There have been two important qualifications to these policies. Monitor, firstly, is also responsible for promoting co-operation (see Chapter 5). It is for NHS commissioners (including Clinical Commissioning Groups, or CCGs), however, to ensure that the appropriate levels of both competition and cooperation exist in their local health economies (HSCA, 2012). Second, NHS England's Five Year Forward View (5YFV), did not mention competition between organisations and instead focussed on how organisations in the NHS need to cooperate with each other, indeed sometimes merge, for example to bring together a range of non-hospital services including GPs and CHS, or to integrate acute inpatient with primary care

3 
services. In November 2014, the Secretary of State for Health Jeremy Hunt) indicated that he did not think that patient choice (that is, competition) was the best way to improve many services (West, 2014). Against this, Monitor's director of cooperation and competition argued that competition still had an important role in the NHS (HSJ, 28th November, 2014). There having been no relevant legislative changes, the HSCA remains in force.

\section{Who was liberated, and what they did when they were}

Data on how many non-NHS providers are entering the NHS quasimarket or their market shares are scarce. The picture - including the one below - therefore has to assembled from various discrepant sources, reporting different kinds of data (for example, numbers of contracts versus numbers of providers versus NHS expenditure on different contracts or different kinds of contractor).

With that proviso, it appears that the mix of NHS funded providers continued to shift towards non-NHS provision in acute (but nonemergency) hospital care, out-of-hours primary care, community health services and general practice. The providers of mental health services and social care were already very diverse. Of the 195 major contracts let competitively in 2013/14, 80 went to corporations and 48 to social enterprises, but the social enterprises' share was larger in cash terms ( $\delta 690 \mathrm{~m}$, versus $£ 490 \mathrm{~m}$ to corporations) (Iacobucci, 2013). In 2015 CCGs held an estimated 15166 contracts with 'nonNHS' providers (Centre for Health and the Public Interest, 2015), on average about 90 per CCG, although many will be contracts with small providers such as small local businesses, charities or individual practitioners. The total value was $£ 9.3 \mathrm{bn}$, about $16 \%$ of CCG budgets, in addition to $\mathcal{E}^{0.6 \mathrm{~b} n}$ worth of such contracts made by NHS trusts (that is, to private providers as subcontractors to these trusts). These figures however must include private sector providers of all kinds, many of which are small local providers (for example, local charities, proprietary care homes) and all services (not just hospitals, but out-ofhours services, community health services, mental health provision, and so on). From 2006/7 to 2014/15, NHS patients treated by nonNHS providers rose from around $0.5 \%(73000)$ to $2.6 \%(471000)$ of all inpatient episodes (over 18 million in total in 2013/14). In 2014 corporations were an estimated $59 \%$ of the private providers contracted to CCGs. Private equity firms backed or owned $58 \%$ of those (Centre for Health and the Public Interest, 2015). 
Private acute hospitals saw a slow rise (to 6\%) in their share of NHS-

funded hospital care, although that $6 \%$ represented about a quarter of their total income (Davis et al, 2015). The private hospitals receiving NHS contracts are mostly corporations, and private provision is concentrated in certain specialties. The private proportion is about a $12.5 \%$ share in trauma and orthopaedics (Appleby, 2015), (within this, $20 \%$ is for hip and knee replacements; see Competition Commission, 2013 ), rising to $34 \%$ in audiology, a very small care group. In outpatient care the proportion of non-NHS providers rose from $0.2 \%(123000)$ to 5.5\% (4.5 million) (Appleby, 2015). These are net increases, though, and some ISTCs have closed while others have been absorbed into the NHS. Accusations that ISTCs have 'cherry-picked' their caseloads appear unsubstantiated (Chard et al, 2011). Rather, 'lemondumping' takes the indirect form of transferring patients who develop complications or become unexpectedly ill back to an NHS hospital. Since private hospitals generally lack the facilities to treat such patients there is an obvious clinical rationale for these transfers. Any 'cherry picking' occurs by default when hospitals are designed - as ISTCs were - only for treating less complex or acutely ill patients: a very different service profile to 'full-service' NHS hospitals. In an earlier period, though, BUPA was alleged (Davis et al, 2015) to have offered some categories of cancer, cardiology and gynaecology patients a cash payment to seek treatment at NHS rather than BUPA hospitals.

Circle abandoned their management-only contract to run Hinchingbrook Hospital as it became unprofitable for them (Scourfield, 2016). PFI schemes also became increasingly financially problematic for NHS Trusts, on average costing about seven times their capital value over the schemes' lifespan (Davis et al, 2015) and, in the meantime, causing unsustainable over-spending in QE Hospital Woolwich, Princess Royal Hospital Orpington, Derby Hospitals and elsewhere. These problems have arisen when inflation has been low, and interest rates exceptionally low, by historical standards.

Evidence about service quality under plural provision is mixed. Two scientific and one 'grey' study each suggest little difference in the outcomes of NHS and ISTC treatment of NHS patients for cataract extraction, inguinal hernia repair, hip replacement, knee replacement and varicose vein surgery (Chard et al, 2011; Competition Commission, 2013). Earlier, Oussedik and Haddad (2009) found that ISTCs had higher rates of post-operative problems for hip and knee replacements, although the difference may partly reflect treatment away 
from the patient's locality of residence rather than provider ownership. Allowing for patients' pre-operative characteristics, ISTCs produced a slightly greater restoration of function after cataract extraction or hip replacement patients than NHS providers did, slightly less for hernia repairs, and no difference for two other treatments. ISTC patients also tended to be healthier, younger and thinner (Browne et al, 2008), however, and tended to be referred for less severe conditions (Chard et al, 2011). An explanation of these mixed findings appears to be that hospital ownership does not in itself affect the level of quality of the average NHS-funded patient's reported experience. The differences are instead entirely attributable to patient characteristics, case-mix differences and unobserved characteristics particular to individual hospitals (Perotin et al, 2013). At least two NHS contracts with corporate providers have been terminated for patient safety reasons (Clinicenta, Lister Hospital Stevenage, 2013; mobile ophthalmology services at Musgrove Park, Taunton, 2014. See Dyer, 2014). A study by Cooper et al, (2011), sometimes irrelevantly cited in this context, reports the effects of competition on in-patient mortality, and not the effects of diverse, still less corporate, hospital ownership.

\section{Community Health and Out-of-Hours Services}

Data by which to compare NHS and non-NHS providers are even more lacking for community health services (CHS). Attempts to convert NHS trusts to social enterprises have been concentrated in mental and community health services. NHS pay and conditions were guaranteed for existing staff but not for new staff, making NHS staff reluctant to exercise their 'right to request' the transfer (Sheaff et al, 2012). Corporate provision of CHS increased from almost nothing in 2010 to a position where corporations, especially Virgin Care, have won some large NHS contracts. In contrast SERCO withdrew altogether from providing NHS-funded clinical services after making multimillion pound losses on them. Similarly, non-NHS providers withdrew from bidding for CHS services in Cambridge, BUPA pulled out of contract negotiations for West Sussex MSK services (Ryan, 2015), and Peninsula Community Interest Company (a social enterprise) refused to re-bid for the mental health services in Cornwall which it had previously provided. By no means universal to begin with, CCGs' use of AQP contracts stagnated from 2013 (Williams, 2014) at about 130 registered providers, usually small to medium sized firms (BMA, 2013), with the largest numbers providing diagnostic and adult hearing services. By 2014 the NHS was also spending about 
f3 billion a year to buy (mostly) CHS or health-related social care 1 from local authorities and charities (Iacobucci, 2014). 2

In out of hours $(\mathrm{OOH})$ services, by 2015 about $51 \%$ of the non 3 general practice providers (44/86) were social enterprises (not for 4 profit organisations), 24\% (21/86) corporate and the same number 5 NHS providers(Warren et al, 2015). 6

$\begin{array}{ll}\text { Without bespoke research it is difficult to ascertain the consequences } & 7\end{array}$ of plural provision for CHS. Existing published data are nugatory 8 and the fuller data-sets, promised for 2015, have yet to be published. 9 The available evidence therefore comes mostly from media reports: a 10 probably biased sample.

Two widely-known reports paint contrasting pictures. The CQC 12 investigation of staff abusing residents with learning difficulties at 13 Winterbourne View (then owned by Castlebeck Care) attributed 14 these problems to inadequate staffing levels and poor care planning. 15 NHS England subsequently announced 'closure or reform of up to $49 \quad 16$ private hospitals that provide long-term accommodation for people 17 with learning disabilities or autism whose behaviour is considered 18 challenging' (Anon, 2016) and a reduction of referrals to private 19 providers. The last large-scale NHS provider of such services (with no 20 allegations of criminal abuse) also closed (Brindle, 2015). In contrast 21 Circle, coordinating some local general practices (but not Bedford 22 Hospital Trust, which refused Circle's contract offer) in providing 23 'integrated' MSK services in Bedfordshire, were claiming to be triaging 24 all patients within 24 hours of referral, to have diverted about a fifth 25 of GP referrals to 'more appropriate' clinicians, and reduced diagnostic 26 and physiotherapy waits: 'All of this for a flat fee, instead of ever rising $\quad 27$ spending' (MSK spokesman, reported in Smith (2015)). 28

Patient informants for the 2012 GP survey evaluated NHS and 29 social enterprise out-of-hours services providers similarly in respect $\quad 30$ of timeliness of care, confidence in the clinician they saw, and overall 31 experience of the service. Corporate providers were evaluated lower 32 ('moderate' to 'large' differences) on all three outcomes (Warren 33 et al, 2015). Commercial providers saw fewer OOH cases per 34 head of population than other providers (NAO, 2014). A CQC 35 investigation into a patient's death in 2008 revealed that the company 36 responsible, Take Care Now, was prone to under-staffing and had weak $\quad 37$ arrangements for managing patient safety, especially considering its 38 heavy use of locum doctors from other European countries. Similar 39 complaints - although no patient deaths - were also reported for 40 SERCO's out-of-hours services in Cornwall, and sharp practice in 41 reporting monitoring data (Comptroller and Auditor General, 2013). 42 


\section{General Practice}

Under the Alternative Provider Medical Services (APMS) scheme, new general practice providers included companies, social enterprises, mutuals, 'groups of existing GPs' (Coleman et al, 2013) and joint bids from Foundation Trusts with out-of-hours care providers, and from private companies with local general practices. Many private primary medical care companies have developed, often partly or wholly GPowned. A FOI enquiry showed that $23 \%$ of GP members of CCGs had a financial stake in a company providing services (though not always primary medical services) to that same CCG (Kaffash, 2013). Virgin ended its partnerships with GPs to prevent this apparent conflict of interest. Often badged as GP-led, the more expansive GPowned companies (for example, Chilvers McCrea Healthcare, DMC Healthcare) had initially won contracts in their local area, and from that basis began winning contracts elsewhere.

Recently large federations of general practices have formed in Northamptonshire, Birmingham, London and elsewhere. Some have added a social enterprise or a looser confederal body as network coordinating body. The federating general practices usually seek economies of scale in management, and some economies of scope in their more specialised clinical services, sharing resources without changing GPs' ownership and management of the practices. A few professional partnership general practices have been taken over by NHS trusts, however (for example, in southern Hampshire; Bostock, 2015).

Doctors' everyday work practices under the APMS contractors appear similar to those in traditional professional partnerships in terms of the division of clinical labour and focus on meeting QOF targets (Coleman et al, 2013). Competition also stimulated at least some 'bad behaviour' on the part of existing providers:

'In Site 1 there were allegations by APPCs that other practices had removed signage and misdirected patients. In Site 2 there were suggestions that staff at a minor injuries service which shared premises with an APPC practice had deliberately misdirected patients away from the APPC' (Coleman et al, 2013).

Again, corporate and proprietary providers would relinquish unprofitable contracts. UHE withdrew from providing NHS-funded primary medical care altogether, and The Practice withdrew from particular contracts (for example, Woking, Leicester, Nottingham). NHS England selected 21 providers to take over at need struggling general practices in southern England. The 21 include NHS 
Foundation Trusts, large merged general practices ('super-practices'), GP federations, out-of-hours co-operatives, Virgin Care, social enterprises and smaller private companies (Pulse 10th July, 2015).

\section{An unstable quasi-market}

The set of NHS contracts which private providers hold is in constant flux, often over short periods. Contracts for, say, $\mathrm{OOH}$ services or planned orthopaedic surgery have shifted between GP cooperatives, NHS trusts and corporate providers (and occasionally back again). Also, the ownership of corporate and proprietary and, to a lesser extent, social enterprise providers has been a succession of mergers, closures, acquisitions and re-naming. For example Virgin acquired and re-named Assura Medical 2010 (except for its property management business, but including Assura's 50\% share in a number of general practices) and, in effect, took over a social enterprise providing CHS. Ramsay acquired Capio UK and its hospitals, day surgery providers and two neurological rehabilitation homes (2007). The Practice took over 30 GP surgeries from Chilvers McCrea, six from United Health and two secure immigration centre clinics from Drummond; and so on.

Despite the aims of competition policy, the NHS quasi-market is not a completely level playing field. On balance, private (especially corporate and proprietary) providers have in certain respects enjoyed less scrutiny and greater freedom of action than NHS providers. Freedom of Information requirements do not apply to non-NHS providers. Private providers can (and do) withdraw from financially damaging contracts, and transfer complex patients away. NHS trusts cannot. Private providers often structure themselves into separate operating and property-holding companies, as a means of converting profits from NHS contracts into interest payments or other ostensible 'costs' which they can then transfer more readily to other recipients (for example, holding companies), and may use off-shore status to reduce their tax payments. The playing-field has also been 'levelled' by limiting NHS providers' access to capital, so that NHS providers can only raise capital through PFI schemes (but see above) or from retained profits, open financial markets or Department of Health loans which follow 'generally accepted principles used by financial institutions' (Department of Health, 2014).

Against this, NHS providers are electorally 'too big to fail'. Monitor has allowed a number of NHS trusts and foundation trusts to continue operating despite being in evident financial difficulty (den Exter and Guy, 2014) (the combined deficits of all NHS trusts and NHS 
foundation trusts being above $£ 500 \mathrm{~m}$ at the end of 2015). Department of Health loans also cover these circumstances.

\section{Trial, error and exit}

For non-NHS providers the coalition government was a period of uncertainty, trial and error as they learned by experience which NHSfunded services they could and could not provide profitably. When it is easier for firms to leave a market than for new ones to enter it (for example, because of investment, 'first mover' or regulatory barriers to entry), a common effect of competition is market concentration on the supply side. Despite what competition legislation (which now applies to the NHS) may intend, seven private providers now have $88 \%$ of the independent provider market for NHS-funded inpatient work (Appleby, 2015).

Certain private providers found it hard to undercut NHS providers' costs and still turn a profit, as noted above. Since about two-thirds of the cost of healthcare is labour (see Chapters 3 and 13), reducing the use of expensive, that is, clinicians', labour is the main way of reducing costs (hence extracting profits) once the level of income from a contract is determined. This may explain the pattern of low staffing levels in some corporate and proprietary providers, of which Serco's out-of-hours service in Cornwall was the most publicised example (Comptroller and Auditor General, 2013). Facing the same cost patterns, however, NHS services are also understaffed at times (Mid Stafford Hospital being the notorious NHS example, see Healthcare Commission, 2009).

\section{The fog of policy}

The above patterns highlight several conceptual distinctions with policy implications.

\section{Corporate versus private}

Occasionally policy-makers themselves distinguish the different kinds of 'private' provision, although sometimes only to advocate one kind of private provider by appeal to another kind (for example, 'GPs are private providers so what is wrong with corporations providing hospital services to the NHS?'). Failure to distinguish leads to overlooking an important health policy scenario somewhat different from that of the NHS purchasing from healthcare corporations. The alternative scenario 
is one of competing public providers, social enterprises, charities and professional partnerships, but without corporate or proprietary providers. It raises the theoretical question of whether competition between public firms (or between social enterprises, or between professional partnerships) would have different loci (for example, speed of access rather than service quality) and consequences than competition between corporations. It also raises the policy question of whether the alleged adverse effects of corporate provision (Davis et al, 2015) can be avoided whilst retaining an element of private provision enabling the introduction of new models of care for NHS patients (for example, hospice care, which originated in the charitable sector).

Competition versus privatisation:

Advocates and opponents of provider plurality both usually equate 15 'competition' with privatisation, demonstrating euphemistic or lax 16 thinking respectively. This failure to distinguish leads to overlooking 17 another important health policy scenario, in which only public 18 providers would compete for patient referrals and NHS contracts. 19 Then provider competition would occur, without any provider 20 plurality. There is some (Cooper et al, 2011; Gaynor et al, 2012) - 21 though contested (Pollock et al, 2011) - evidence that competition 22 between predominantly NHS providers may reduce hospital mortality 23 for acute myocardial infarction patients. If so, competition between 24 NHS providers produces at least some of the benefits of competition 25 whilst non-NHS providers play a marginal role. US evidence also 26 suggests that it is competition, not ownership, which affects provider $\quad 27$ behaviour (Allen, 2009). 28

The NHS contains two different structures for provider competition. $\quad 29$

1. Competition for patients ('competition in the market'), that is, to 31 attract self- and GP referrals, each referral triggering a payment to 32 the provider. In this structure, plural providers can permanently 33 coexist and compete in each local health economy. 34

2. Competition for contracts, ('competition for the market', 'managed 35 competition'; Saltman and von Otter, 1992) under which providers 36 compete for a usually time limited local monopoly to provide a 37 service or groups of services. If a private provider wins, the result 38 may be private provision without further competition. 39

Even if plural provision were necessary (which it is not: see above), 41 it is also insufficient to stimulate provider competition for patients. 42 
Supposing GPs abandoned their professional dislike of competing for patients, they would still have neither need nor reason to compete wherever the demand for general practice services exceeds the supply (that is, almost everywhere). The price of provider competition is an excess of supply over demand, or for the NHS over healthcare needs, irrespective of provider ownership (Dawson, 1994).

\section{Policy messes}

'Policy messes' arise when implementing one policy obstructs implementation of another (Winetrobe, 1992). Provider plurality seems to cause at least three.

\section{Plural Provision versus Austerity:}

Both Labour and the Coalition government responded to the 2008 financial market crash by cutting public expenditure, including NHS spending in real-terms, if not cash. At present (early 2016) NHS England and Monitor are proposing to reduce tariff prices by $7 \%$ overall and more than $10 \%$ for some orthopaedics work, a change predicted (Anon, 2015) to reduce private orthopaedics hospitals' income by $7 \%$ in $2016 / 17$. As also noted above, private providers tend to withdraw from bidding for, or even keeping, unprofitable NHS contracts. Austerity seems to force governments to choose between cost containment and provider plurality.

\section{Plural Provision versus Integrated Care:}

Treating patients with multiple chronic conditions effectively requires combining separate clinical or therapeutic activities, often undertaken by different providers, into a coherent 'integrated' sequence of activities across often different settings (see Chapter 9). The more providers are involved, the more organisational interfaces these patients' care has to be coordinated across, and the harder it becomes to achieve the continuities of care (Sheaff et al, 2015). This is an argument for of having general practice, community health services and perhaps community hospital services provided by a single organisation rather than having a greater plurality of providers in each locality. The Five Year Forward View tacitly takes the point and opts for integrated care. 
Plural Provision versus Political Accountability:

Supporters and opponents of plural provision respectively tend to

assume that provider plurality will markedly improve or worsen the accessibility, provision, development or cost of NHS-funded services. Central regulation and mandated local commissioning practices may so tightly constrain all providers, however, that their ownership makes little difference to these policy outcomes. Evidence based medicine and professional bodies' disciplinary influence are equally agnostic about provider ownership (Andersen, 2009). In those circumstances the only coherent rationales for plural provision would be ideological or to satisfy vested interests outside the health sector. (Davis et al, 2015, report the numbers of Conservative - and other parties' - MPs with financial interests in private healthcare provision.)

\section{Dismantling the NHS?}

Current English health policy is therefore rather ambivalent, even coordination ('commissioning') agency exercising governance over 25 mostly independent providers. A standard riposte is that the NHS 26 was established to guarantee patients' access to needed healthcare free $\quad 27$ of charge; provider ownership doesn't matter if the quality and cost 28 of NHS services are good (Appleby, 2015). Provider plurality might 29 make a difference in precisely these terms, though, and it remains to 30 be shown whether it is for the better. Otherwise, what is the health 31 gain from provider plurality? 32

\section{References}

Allen, P, 2006, New localism in the English NHS: what is it for? Health 36 Policy, 79(2-3), 244-52 37

Allen, P, 2009, Restructuring the NHS again: supply side reform 38 in recent English Healthcare policy, Financial Accountability and 39 Management, 25, 4, 343-89 40 
Allen, P, 2013, An economic analysis of the limits of market based reforms in the English NHS, BMC Health Services Research, 13(Suppl. 1), $\mathrm{S} 1$

Allen, P, Jones, L, 2011, Increasing the diversity of health care providers, in N Mays, L Jones, A Dixon (eds), Understanding New Labour's market reforms of the English NHS, London: Kings Fund

Allen P, Bartlett W, Zamora B, Turner S, 2011, New forms of provider in the English National Health Service, Annals of Public and Cooperative Economics, 82, 1, 77-95

Allen, P, Petsoulas, C, Ritchie, B, 2014, Final report from study of the use of contractual mechanisms in commissioning, Canterbury: Policy Research Unit on Commissioning and the Healthcare System.

Andersen, LB, 2009, What determines the behaviour and performance of health professionals? Public service motivation, professional norms and/or economic incentives, International Review of Administrative Sciences, 75, 1, 79-97

Anon, 2015, Prices for private providers to drop by $7 \%$ under new NHS price structure, National Health Executive, 16 December

Anon, 2016, Responses to the abuse of people with learning disabilities and autism and Winterbourne View, British Institute of Learning Disabilities (BILD) News and What's On web-page, http://www. bild.org.uk/news-and-whats-on/winterbourne-view, accessed 15 April 2016

Appleby, J, 2015, Paid for by the NHS, treated privately, British Medical Journal 350, ph3109

Bacon, R, Eltis, W, 1976, Britain's economic problem: Too few producers, London: Macmillan

Bartlett, W, Le Grand, J, 1993, Quasi-markets and Social Policy, London: Palgrave Macmillan

BMA, 2013, Understanding the reforms... Choice and any qualified provider. London: BMA Health Policy and Economic Research Unit

Bostock, N, 2015, Vanguard GPs open shared branch surgery to deliver seven-day access for 70,000 patients, GPonline, 2 September

Brindle, D, 2015, NHS to shut many residential hospitals for people with learning disabilities, The Guardian, 10 February.

Browne J, Jamieson L, Lewsey J, Meulen J van der, Copley L, Black N, 2008, Case-mix and patients' reports of outcome in Independent Sector Treatment Centres: Comparison with NHS providers, BMC Health Services Research, 8, 1, 78

Centre for Health and the Public Interest, 2015, The contracting NHS: Can the NHS handle the outsourcing of clinical services? London: Centre of Health and the Public Interest 
Chard J, Kuczawski M, Black N, van der Meulen J, on behalf of 1 the POiS Audit Steering Committee, 2011, Outcomes of elective 2 surgery undertaken in independent sector treatment centres and 3 NHS providers in England: Audit of patient outcomes in surgery. 4 BMJ 343, d6404

Coleman A, Checkland K, McDermott I, Harrison S, 2013, The limits of market-based reforms in the NHS: The case of alternative providers in primary care, BMC Health Services Research, 13(Suppl 1), S3

Competition Commission, 2013, Private Healthcare Market Investigation, London: Competition Commission

Comptroller and Auditor General, 2013, Memorandum on the provision of the outofhours GP service in Cornwall, London: National Audit Office.

Cooper Z, Gibbons S, Jones S, McGuire A, 2011, Does hospital competition save lives? Evidence from the English NHS patient choice reforms, The Economic Journal, 121, 554, F228-60

Davis, J, Lister, J, Wrigley, D, 2015, NHS for sale: Myths, lies and 16 deception, London: Merlin

Dawson, D, 1994, Costs and prices in the internal market: Markets vs the NHS management executive guidelines, York: CHE, University of York.

Department of Health, 2010a, Equity and excellence: Liberating the NHS, London: Department of Health.

Department of Health, 2014, Guidance on financing available to NHS trusts and Foundation Trusts, www.gov.uk/government/publications/ guidance-on-financing-available-to-nhs-trusts-and-foundation-trusts

Department of Health, 2006, Health reform in England: update and commissioning framework, London: Department of Health, http:// webarchive.nationalarchives.gov.uk/20130107105354/http:// www.dh.gov.uk/en/Publicationsandstatistics/Publications/ PublicationsPolicyAndGuidance/DH_4137226

Department of Health, 2007a, Health reform in England: Update and next steps, http://webarchive.nationalarchives.gov.uk/+/ www.dh.gov.uk/en/Publicationsandstatistics/Publications/ PublicationsPolicyAndGuidance/Browsable/DH_4125573

Department of Health, 2007b, Options for the future of Payment by Results 2008/9 to 2010/1, London: Department of Health

Department of Health, 2010b, Principles and rules for cooperation and competition (revised edition), London: Department of Health 
den Exter, A, Guy, M, 2014, Market competition in health care markets in the Netherlands: Some lessons for England? Medical Law Review, $22,2,255-73$

Gaynor, M, Moreno-Serra, R, Propper, C, 2012, Can competition improve outcomes in UK health care? Lessons from the past two decades, Journal of Health Services Research and Policy, 17(Suppl 1), 49-54

Harding, A, Preker, A, 2000, Understanding organizational reforms: The corporatization of public hospitals

Healthcare Commission, 2009, Investigation into Mid Staffordshire NHS Foundation Trust, London: Healthcare Commission.

Hellowell, M, 2014, The return of PFI: Will the NHS pay a higher price for new hospitals? London: Centre of Health and the Public Interest Hodge, K, 2013, In-debt South London Healthcare NHS Trust 'should be broken up' The Independent, 8 January.

House of Commons Health Select Committee, 2006, Independent Sector Treatment Centres, London: House of Commons

Iacobucci, G, 2014, A third of NHS contracts awarded since health act have gone to private sector, BMJ investigation shows. BMJ, 349, g7606

Iacobucci, G, 2013. More than a third of GPs on commissioning groups have conflicts of interest, BMJ investigation shows. BMJ, 346, f1569 Jones, L, Mays, N, 2013, Early experiences of any qualified provider, British Journal of Healthcare Management, 19, 5, 217-24

Kaffash, J, 2013, Revealed: One in five GPs on CCG boards has financial interest in a current provider, Pulse Today, www.pulsetoday. co.uk/news/commissioning/commissioning-topics/ccgs/revealedone-in-five-gps-on-ccg-boards-has-financial-interest-in-a-currentprovider/20004369.fullarticle

Letwin, O, 1988, Privatising the world: A study of international privatisation in theory and practice, Cassell

Lipsey, RG, Lancaster, K, 1956, The general theory of the second best, The Review of Economic Studies, 24, 1, 11-32

Monitor, NHS foundation trust directory, www.gov.uk/government/ publications/nhs-foundation-trust-directory/nhs-foundation-trustdirectory\#what-are-foundation-trusts

NAO (National Audit Office), 2014, Out-of-hours GP services in England, London: National Audit Office, www.nao.org.uk/report/hours-gpservices-england-2/

Offe, C, 1982, Some contradictions of the modern welfare state, Critical Social Policy 2, 5, 7-16 
Oussedik, S, Haddad, F, 2009, Further doubts over the performance 1 of treatment centres in providing elective orthopaedic surgery, Journal 2 of Bone and Joint Surgery, British Volume, 91-B, 9, 1125-6 3

Perotin V, Zamora B, Reeves R, Bartlett W, Allen P, 2013, Does 4 hospital ownership affect patient experience? An investigation 5 into public-private sector differences in England, Journal of Health 6 Economics, 32, 3, 633-46

Pollock AM, Dunnigan MG, Gaffney D, Price D, Shaoul J, 1999, 8 Planning the 'new' NHS: Downsizing for the 21st Century, BMJ 9 319(7203), 179-84 10

Pollock A, Macfarlane A, Kirkwood G, Majeed FA, Greener I, Morelli 11 C, et al, 2011, No evidence that patient choice in the NHS saves 12 lives, The Lancet, 378(9809), 2057-60 13

Ryan, S, 2015, 'Bupa CSH pulls out of West Sussex MSK contract 14 negotiations', The Argus, 26 January 15

Saltman, RB, von Otter, C, 1992, Planned Markets and Public 16 Competition, Buckingham: Open University Press 17

Scourfield, P, 2016, Squaring the Circle: What lessons can be learned 18 from the Hinchingbrooke franchise fiasco? Critical Social Policy, 36, 19 1, 142-52 20

Sheaff R, Halliday J, Øvretveit J, Byng R, Exworthy M, Peckham S, 21 2015, Integration and Continuity of Primary Care: Polyclinics and 22 Alternatives, an Organisational Analysis, Health Services and Delivery 23 Research, 3(35) 24

Sheaff, $\mathrm{R}$ et al[[please provide remaining author names]], 2012, 25 Understanding professional partnerships and non-hierarchical organisations, 26 London: NIHR-SDO 27

Smith, W, 2015, What Circle has learned from its Bedford MSK 28 contract, Health Services Journal, 7 October. 29

Warren, C, Abel, G, Lyratzopoulos, G, Elliott, M, Richards, S, Barry, 30 H, Roland, R, Campbell, J, 2015, Characteristics of service users 31 and provider organisations associated with experience of out of hours 32 general practitioner care in England: Population based cross sectional 33 postal questionnaire survey, BMJ, 350, h2040 34

West, D, 2014, Exclusive: Patient choice is not key to improving 35 performance, says Hunt, Health Services Journal, 26 November 36

Williams, D, 2014, CCG interest in 'any qualified provider' scheme 37 dwindles, Health Services Journal, 11 September. 38

Winetrobe, BK, 1992, A tax by any other name: The Poll Tax and the 39 Community Charge, Parliamentary Affairs, 45, 3, 420-7 40 